metre, or all the molecules in a slice of $1 / 10,000$ of the thickness of that cube. Think of a cube filled with particles, like these glass balls, ${ }^{1}$ scattered at random through a space equal to 1,000 times the sum of their volumes. Such a crowd may be condensed (just as air may be condensed) to $\mathrm{I} / \mathrm{I}, 000$ of its volume; but this condensation brings the molecules into contact. Something comparable with this may be imagined to be the condition of common air of ordinary density, as in our atmosphere. The diagram with size of each molecule, which, if shown in it to scale, would be I millimetre (or too small to be seen by you), to represent an actual diameter $1 / 10,000,000$ of a centimetre, represents a gas in which a condensation of I to Io linear, or I to 1,000 in bulk, would bring the molecules close together.

Now you are to imagine the particles moving in all directions, each in a straight line until it collides with another. The average length of free path is ten centimetres in our diagram, representing $\mathrm{I} / \mathrm{r} 00,000$ of a centimetre in reality. And to suit the case of atmospheric air of ordinary density and at ordinary pressure, you must suppose the actual velocity of each particle to be 50,000 centirnetres per second; which will make the average time from collision to collision $\mathrm{I} / 5,000,000,000$ of a second.

The time is so far advanced that I cannot speak of the details of this exquisite kinetic theory, but I will just say that three points investigated by Maxwell and Clausius-viz. the viscosity, or want of perfect fluidity of gases; the diffusion of gases into one another; and the diffusion of heat through gases-all these put together give an estimate for the average length of the free path of a molecule. Then a beautiful theory of Clausius enables us from the average length of the free path to calculate the magnitude of the atom. That is what Loschmidt has done, ${ }^{2}$ and I, unconsciously following in his wake, have come to the same conclusion; that is, we have arrived at the absolute certainty that the dimensions of a molecule of air is something like that which I have stated.

The four lines of argument which I have now indicated, lead all to substantially the same estimate of the dimensions of molecular structure. Jointly they establish, with what we cannot but regard as a very high degree of probability, the conclusion that, in any ordinary liquid, transparent solid, or seemingly opaque solid, the mean distance between the centres of contiguous molecules is less than the $1 / 5,000,000$, and greater than the I/I,000,000,000 of a centimetre.

To form some conception of the degree of coarsegrainedness indicated by this conclusion, imagine a globe of water or glass, as large as a football, ${ }^{3}$ to be magnified up to the size of the earth, each constituent molecule being magnified in the same proportion. The magnified structure would be more coarse-grained than a heap of small shot, but probably less coarse-grained than a heap of footballs.

\section{SMOKE ABATEMENT}

$\mathrm{A} \mathrm{N}$ important meeting was held in the Egyptian Hall of the Mansion House on Monday last, to take further steps towards the abolition, or at all events the reduction, as far as possible, of the smoke nuisance. The Lord Mayor presided, and the following among others

${ }^{1}$ The piece of apparatus now exhibited, illustrated the collisions taking place between the molecules of gaseous matter, and the diffusion of one gas into another. It consisted of a board of absut one metre square, perforated with soo holes in ten rows of ten holes each. From each hole was suspended a cord five metres long. To the lower end of each cord in five contiguous rows. there was secured a blue csloured glass ball of four centimetres diameter; and similarly to each cord of the other five rows, a red coloured ball of the same size. A bail from one of the outer rows was pulled aside, and, being set free, it plunged in amongst the others, causing collisions throughout the whole plane in which the suspended balls were situated.

2 Sitzungsberichte of the Vienna Academy, Oct. 12, 1865, p. 395.

3 Or say a globe of 16 centimetres diameter. were present:-The Duke of Northumberland, the Duke and Duchess of Westminster, Sir William Siemens, Sir Frederick Abel, Sir Lyon Playfair, M.P., Sir Frederick Pollock, Sir T. Spencer Wells, Mr. George Cubitt, M.P., Dr. Farquharson, M.P., Col. Makins, M.P., Capt. Galton, Mr. Edwin Chadwick, C.B., Mr. Ernest Hart, Mr. C. Waring, the Hon. Rollo Russell, General Lowry, C.B., Mr. George Shaw (chairman of the City Commission of Sewers), Mr. W. R. E. Coles, Mr. W. Chandler Roberts, of the Royal Mint, and Mr. Gregory, Master of the Clothworkers' Company.

The proceedings were opened by the reading of a Report, which has been carefully prepared by the Council, detailing the steps which have already been taken, and giving particulars of the exhibitions of last year in London and Manchester. The Report also deals with the work which has been done regarding the chemical composition of smoke by Prof. Chandler Roberts, and the many tests of coal made by Mr. Clark. In this important investigation, attention was called to the fact that a very great discrepancy exists between the heating efficiency of various types of grates, stoves, furnaces, and the like. In some forms of grate, for instance, only 22 per cent. of the total heat is utilised, whilst others require nearly three tons of coal to do the same work which other stoves manage to get out of one ton.

The Council desired to report that, so far as they had been able to ascertain, the most marked benefit resulting from the movement had been in the increased use of gas and coke for heating purposes. The improvement in gasheating apparatus had been considerable, and the use of coke had been greatly facilitated by its being supplied to the public in more convenient sizes than formerly, and by the introduction of firebrick or other slow-conducting substances used in the fireplaces for burning it. The use of smokeless coal had also been extended in the metropolis; but the Council found that the description of such coal supplied was in a large number of instances unsuitable or inferior, and from that cause, coupled with the fact that smokeless coals were not generally supplied by coal merchants, there had not been, so far, any very marked increase in its consumption. Marked improvement had, however, been made in open grates and stoves for burning that description of coal, and one firm of manufacturers, who brought out a cheap stove at the South Kensington Exhibition, had sold upwards of i4,000 during the past two years; and they remarked that the public seemed ready to burn non-smoky coal if proper stoves for using it were offered at a reasonable price. Appliances for improving the draught of chimneys had also been introduced lately, and that tended to facilitate the use of smokeless coal. The Council had examined the present state of the administration of the law for the suppression of smoke, and they considered that in view of the enormous extension of buildings and factories in London and large towns, and in view also of the evidence that smoke could be to a great extent, if not entirely, avoided, the scope of legislative enactments for abating smoke should be extended and their provisions duly enforced.

One part of the Report deals with a matter to which we attach the greatest importance. It is suggested that there should be some place which the public can visit and where they may examine any apparatus that is approved of, or which they may wish to purchase; but above this it is pointed out that a place is requisite where scientific, chemical, and other tests may be made for the information of the public generally, but especially for the help of inventors and manufacturers who may wish to try new suggestions. The Report also suggests that in connection with this there should be some place for discussion and public lectures, for the general advancement and diffusion of knowledge touching smoke abatement. The third proposal is certainly the most doubtful one, but the 
first and second are so important that the less time that is lost in starting such an institution the better; and we are glad to learn that towards its foundation the Duke of Westminster has promised 500 l., Mr. C. Waring Iool., and Mr. Cubitt 1ool.

The most important speech, perhaps, was that made by the Duke of Westminster, in moving the adoption of the Report. He pointed out that we are face to face with a very gigantic evil-an evil not only gigantic in itself, but, considering the enormous yearly increase of 40,000 in the population, one of a very alarming character. Therefore it was necessary that some steps should be taken to abate, if not to entirely do away with, that monstrous evil, which affected the health and vitality of the inhabitants of the metropolis. They were all aware of the evil effects of smoke, and how far worse it became when mixed with fog, but they believed that it was an evil which might be considerably modified if not entirely prevented. They had indisputable authority for saying that smoke was very wasteful and destructive. The waste in London alone amounted to one million yearly, and the waste in the country must be taken in proportion to that in the metropolis. They had also the highest authority for informing the public that the evil affected the health of those who lived under the canopy of smoke. Its effect on public buildings was also most destructive, and Mr. Shaw-Lefevre had said that to repair the damage done by its agency to the Houses of Parliament alone involved an expenditure of $2500 l$. per annum, and there could be no greater curse and bane to the metropolis than that smoke nuisance. The object of the meeting was to impress upon the public the importance of the subject. The Smoke Nuisance Act had been useful in the past, and could be made more efficacious in the future if its provisions were more strenuously enforced. Quoting from the correspondence which had taken place between the Home Office and the Association upon the subject, the speaker said that the Home Secretary had stated that in the majority of cases the fines inflicted were far less in amount than had been contemplated by the Act. That was not a right state of things, and efforts should be made to remedy it as soon as possible; and it was not unreasonable to suppose that with proper enforcement of the law a check to a certain extent might be put upon the nuisance. After sonie other observations, his Grace concluded by moving the adoption of the Report.

Sir Spencer Wells and Sir Frederick Abel spoke in favour of the Duke of Westminster's proposal, which was carried unanimously.

The next resolution was moved by the Duke of Northumberland, and was to the following effect :- " That the period has now arrived at which systematic inquiry is desirable into the application of the resources of technical science for the abatement of smoke now largely produced in industrial processes and in the heating of houses, as well as into the operation of the existing laws for smoke abatement; and that the Council of the National Smoke Abatement Institution be requested to urge upon the Government the desirability of appointing a Royal Commission for the purpose."

This was seconded by Sir Wm. Siemens and carried.

We are glad to see that it was acknowledged that the stated objects of the Smoke Abatement Institution, and the success which has attended its past efforts, had established a claim not only to the support of the meeting, but to that of the City of London and other great cities and towns.

We must congratulate the Council of the new institution upon the energy which they are displaying, and we believe that in a few years the success they will then have met with will lead one to hope that in process of time the smoke nuisance which kills its tens of thousands annually, and makes life in a great city like London almost unbearable, will to a certain extent be done away with.

\section{NOTES}

GREAT efforts are being made by the Council of the Society of Arts and its chairman, Sir William Siemens, who has again been elected to this office, to make their conversazione, to be held on the 25th inst. at the Fisheries Exhibition, a great success. The fountains are to be illuminated by coloured fires, and the gardens, as well as the Exhibition Buildings, will be lighted by the electric light. The band of the 6th Thuringian Regiment of German Infantry will perform in the building.

A MEeTing which may have an important result upon science and art instruction in this country has been inaugurated at Manchester. An association has been established to effect the general advancement of the profession of science and art teaching by securing improvements in the schemes of study and the establishment of satisfactory relations between teachers and the Science and Art Department, the City and Guilds of London Institute, and other public authorities. It proposes also to collect such information as may be of service to teachers professionally, and it will endeavour by constant watchfulness to advance the status and material interests of science and art teachers in all directions. The president of the new Association is Prof. Huxley, and the vice-presidents are Dr. H. E. Roscoe, Mr. Norman Lockyer, Prof. Boyd Dawkins, Prof. Gamgee, Prof. Ayrton, Prof. Silvanus Thompson, Dr. John Watts, Mr. S. LeighGregson, Mr. John Angell, Mr. W. Lockett Agnew, Mr. C. M. Foden, and Mr. J. H. Reynolds. Mr. W. E. Crowther, of the Technical School and Mechanics Institution, Manchester, is the Honorary Secretary, and all communications should be addressed to him, especially by those who are desirous of formin affiliated unions in other districts. We believe that branches are already being established at Newcastle-upon-Tyne and Liver pool.

DR. J. H. GiLbert, F.R.S., has been elected a Corresponding Member of the Institute of France (Academy of Sciences).

The treasurer of the Darwin Memorial Fund has reseived through Dr. Elforing of Helsingfors a cheque for $94 l .4$ s., that being the amount collected in Finland as a contribution to the memorial. That so large an amount should have been collected in so small a country is only an additional proof of the ready recognition which the great works of Darwin have received in other countries as well as our own. The fund now amounts to $3300 \%$.

THE Lick Observatory, we learn from Science, has made much progress during the past year. The dome for the small equatorial has now been finished, and is certainly the most complete and convenient one of its size in America. The building of the observatory in which the great thirty-six.inch equatorial is to be placed is also progressing. The walls of the main building are half completed, and the cellar for the dome has been excavated. The four-inch transit-house and the buildings for the photoheliographs have been in working order now for some time, as they were used in a successful observation of the transit of Venu; last December. In a few weeks the building for the meridian circle will be commenced, as well as a house for the astronomers and buildings to contain the appliances for moving the dome, and for the general heating and lighting of the observatory. Two brick reservoirs for spring water, the one containing 83,000 gallons, the other 20,000 gallons, have been constructed, and another reservoir to contain 83,050 gallons of rain-water will shortly be commenced. The roads have been extended. Some of the original arrangements of the observatory buildings, which were only provisional, have now been replaced by more substantial and permanent structures, and by the end of the season great progress will have been made. 